\title{
Multi-objective optimal crop plan for optimum groundwater utilization considering profit maximization: A case study
}

Kamalika Nath ( $\square$ kamalikanath@gmail.com )

ICAR Indian Agricultural Statistics Research Institute

Rajni Jain

ICAR-National Institute of Agricultural Economics and Policy Research

Alka Arora

ICAR Indian Agricultural Statistics Research Institute

Himadri Shekhar Roy

ICAR Indian Agricultural Statistics Research Institute

Sudeep Marwaha

ICAR Indian Agricultural Statistics Research Institute

\section{Research Article}

Keywords: Crop planning, Genetic Algorithm, NSGA, Optimization, Pareto optimal solution

Posted Date: January 18th, 2022

DOI: https://doi.org/10.21203/rs.3.rs-1194487/v1

License: @ (i) This work is licensed under a Creative Commons Attribution 4.0 International License. Read Full License 


\section{Abstract}

This paper presents a multi-objective optimization problem to identify an optimal crop plan by simultaneously maximizing profit and reducing groundwater utilization. An important economic and sustainable agricultural decision-making task is to make optimal use of resource constraints in a given planting period. To solve the problem, the NSGA II and NSGA III algorithms are used. The performance and effectiveness of both algorithms are examined by comparison of the results. In addition, the Pareto fronts are presented with graphical comparisons. The findings show that NSGA-III is a more viable tool than NSGA II to solve an optimal crop planning problem.

\section{Highlights}

I. Identification of optimal crop plan by simultaneously maximizing profit and reducing groundwater utilization.

II. Development of Multi-objective optimal crop plans for efficient use of groundwater as well as profit maximization.

III. Development of optimal crop plans by Non-dominated Sorting Genetic Algorithms (NSGA-II and NSGA-III) for optimal groundwater utilization.

IV. Examination of the performance and effectiveness of both algorithms.

\section{Introduction}

Agriculture is the livelihood source for more than half the population of India, but several production factors make it more complex and uncertain. Therefore, it is an overriding task for decision-makers, researchers, and policymakers to improve farmers' revenue. Developing advanced techniques and appropriate management contributes towards the desired objective of agricultural planning and policy development. Therefore, it has become essential to optimize various limited resources so that profit, production, and productivity are maximized. Several factors influence farmer income, including crop yield, resource use efficiency, cropping intensity, and so on. The crop planning practice is based on many factors, such as land types for cultivation, meteoric conditions, precipitation, irrigation system, groundwater, and available agricultural inputs such as machinery, fertilizer, capital, labour, production costs, and so on. A crop plan is important for agricultural water management also, and it can decide what proportion of water should be allocated to different cropped areas in obtaining certain goals like the maximization of profit from cultivated land under the limitation of land and water resources (Zeng et al., 2010). Several researchers (Kuo et al., 2000; Raju and Kumar, 2004; Olakulehin and Omidiora, 2014 and Mansourifar et al., 2013) used Genetic Algorithm (GA) to maximize benefit from different cropping patterns. Sarma et al. (2006), Annepu et al. (2011), and Sadati et al. (2014) investigated GA to identify optimal crop plans by considering the several constraints to maximize net profit. In agriculture, it is critical to not only optimize one objective but also to develop optimal resourcesaving crop planning by optimizing several objectives simultaneously. The decision-making process becomes complicated due to the multi-objective characters. In this way, the agricultural system and crop planning become complex and multiple conflicting objectives need to be addressed simultaneously (Xevi and Khan, 2005). The solution of such problems is different from that of a single-objective optimization problem Multi-objective optimization problems normally produce not one but a set of solutions that are all equally good. A wide variety of nature-inspired and evolutionary algorithms (EA's) have been used to solve optimization problems consisting of only one objective function. In recent years, nature-inspired optimization algorithms gained popularity to tackle multi-objective problems due to their profound efficiency to solve numerous complex problems in several fields of science. A non-dominated sorting genetic algorithm-II (NSGA-II) was developed to overcome various issues (Deb et al., 2002) related to Multi-Objective Evolutionary Algorithms (MOEA). NSGA (Jarin et al., 2006) was also applied for the crop planning model to maximize total net benefit and minimize total cost. NSGA-Il (Pal et al., 2009; Lalehzari et al., 2016; Sarker and Ray, 2009; Yusoff et al., 2011 and Fanuel et al. 2018) gains much popularity to solve multi-objective crop planning problems, water irrigation problems, etc. and in contrast to the strategy of single-objective optimization, NSGA-II optimizes every objective independently. To tackle some disadvantages of NSGA-II, related to mainly two and three objectives, Deb, K. and Jain, H. (2013) and Jain, H. and Deb, K. (2013) introduced reference-point based NSGA-III algorithm. NSGA-III (Mwiya et al., 2020), an advanced version of NSGA-II, was investigated to maximize net benefits and water use efficiency and minimization of risk.

The paper is arranged accordingly. A mathematical model for the crop planning problem is presented in section 2.1. Section 2.2 and 2.3 provide a short description of the features of multi-objective methods employed. Section 3 describes the data used in the study and its sources. Section 4 provides the results and discussions. In the final section, we summarize the findings and future directions for research.

\section{Materials And Methods}

\subsection{Model formulation}

In the present section, the required mathematical formulation of the model is presented. An objective function and a set of constraints are described below.

\section{Objective functions}

The problem of crop planning formulated for the study has two goals. At the same time, the model maximizes profit and minimizes groundwater use that irrigates crops. The goal is to use the limited resources effectively to determine the allocation of land for several crops to be planted annually. The objectives and constraints of the optimization model are:

\section{Objective function 1 :}


Maximize $\mathrm{Z}_{1}=\sum_{\mathrm{i}}^{\mathrm{n}}\left[\left(\mathrm{Y}_{\mathrm{i}}{ }^{*} \mathrm{P}_{\mathrm{i}} * \mathrm{~A}_{\mathrm{i}}\right)-\left(\mathrm{C}_{\mathrm{i}} * \mathrm{~A}_{\mathrm{i}}\right)\right]$

Objective function 2 :

Minimization of irrigation water: The volume of groundwater to be used for irrigating the crops will be minimized due to the shortage of water in the study area.

$$
\operatorname{Minimize}_{2}=\sum_{\mathrm{i}=1}^{\mathrm{n}}\left(\mathrm{W}_{\mathrm{ri}} * \mathrm{~A}_{\mathrm{i}}\right)
$$

2

Constraints

i. Ground-water constraints: $\sum\left(\mathrm{W}_{\mathrm{ri}}{ }^{*} \mathrm{~A}_{\mathrm{i}}\right) \leq \mathrm{W}_{\mathrm{t}}(3)$

The groundwater usage should be less than or equal to groundwater available for agriculture.

ii. Constraint regarding total available area for cultivation: $\sum A_{i} \leq A_{t}(4)$

The sum of land area used for the cultivation of all crops in a given season must be less than or equal to the total available land area

iii. Non-negative constraints: $A_{i} \geq 0$ (5)

iv. Min-max area constraints: $\mathrm{L}_{\mathrm{bi}} \leq \mathrm{A}_{\mathrm{i}} \leq \mathrm{U}_{\mathrm{bi}}(6)$

Crop area must fall within a given boundary.

\section{Notations}

$\mathrm{i}=1,2 \ldots \mathrm{n}$

$n=$ Number of crops considered in the study area; $n=14$ (for kharif season) and $n=11$ (for rabi season)

$\mathrm{Z}_{1}=$ Net profit (Rs)

$\mathrm{Z}_{2}=$ groundwater use

$\mathrm{Y}_{\mathrm{i}}=$ Yield of $\mathrm{i}^{\text {th }}$ crop per unit area $(\mathrm{kg} / \mathrm{ha})$

$\mathrm{P}_{\mathrm{i}}=$ Price of each crop in the market (both main product and by-products) (Rs/kg)

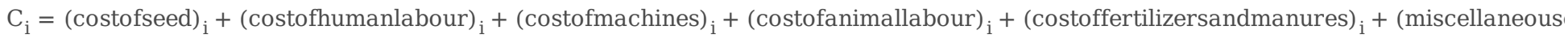

$\mathrm{W}_{\mathrm{ri}}=$ Water requirement for each Crop (cubic meter)

$\mathrm{W}_{\mathrm{t}}=$ Total available water (cubic meter)

$\mathrm{A}_{\mathrm{i}}=$ Area under ith crop (thousand hectares)

$\mathrm{A}_{\mathrm{t}}=$ Total available area for cultivation (thousand hectares)

$\mathrm{L}_{\mathrm{bi}}=$ Lower bound of area for each crop (thousand hectares)

$\mathrm{U}_{\mathrm{bi}}=$ Upper bound of area for each crop (thousand hectares)

\subsection{Non-Dominated Sorting Genetic Algorithm II (NSGA-II)}

The NSGAll may be a second-generation MOEA developed by Deb et al. (2002) which improved upon the original NSGA by employing a more efficient nondomination sorting scheme, removing the sharing parameter, and adding an implicitly elitist method of selection that greatly helps to capture Pareto surfaces (Wang et al. 2011). In addition, the NSGA-II can handle both real and binary representations (Wei et al., 2009). NSGA-II was used in earlier crop planning studies successfully (Sarker and Ray 2009). The concept of Pareto-dominance is employed to assign fitness values to the sampling solutions. For instance, $\mathrm{X} 1$ dominates $\mathrm{X} 2$ if and only if it performs as well as $\mathrm{X} 2$ in all objectives and better in at least one objective. The fast-non-domination sorting approach of the NSGA-II ranks each solution consistent with the number of solutions that dominate it. Once fitness is assigned, a two-step crowded binary tournament selection is performed. In cases where two solutions have different ranks, the individual with the inferiority is preferred. Alternatively, if both solutions possess an equivalent rank, then the answer with the larger crowding distance is preferred. Solutions with higher crowding distances add more diversity to the answer population, which helps to make sure that the NSGA-II finds solutions along with the complete extent of the Pareto surface. A detailed step-by-step procedure is given in Figure 1 -

\subsection{Non-dominated sorting algorithm-III}


NSGA-II is extended and modified to NSGA-III (Deb \& Jain, 2014; Jain \& Deb, 2014) to improve the performance and efficiency of the algorithm. NSGA-II provides a set of Pareto optimal solutions which becomes problematic when the number of objective functions increases. Both NSGA-II and NSGA-II generate an initial random population of size N. In the case of NSGA-III, every solution represents a feasible scaling plan as described by Yannibelli et al. 2020. During the initial phase, both algorithms use similar kinds of evolutionary cycles such as the crossover and mutation operators. An offspring population is generated by NSGA-II using the same stage of mutation and crossover as NSGA-II. But in the case of selection mechanism, NSGA-III uses a different mechanism to create a new population for the next generation. A new population is created using for the successive generation from the combined current and offspring population. The termination criterion followed in NSGA-III is similar to NSGA-III. After achieving the termination criterion, NSGA-III generates a Pareto set of population corresponding to the final generation.

\section{Data Description}

The study is mainly constructed on data composed from the "Comprehensive Scheme for Studying the Cost of Cultivation (CoC) of Principal Crops", Directorate of Economics and Statistics, Ministry of Agriculture, Government of India (https://eands.dacnet.nic.in/Cost_of_Cultivation.htm). Beneath this scheme, data were assembled from a sample of $300 \mathrm{farm}$ households in 30 tehsils spread across three agro-climatic zones of Punjab. The other secondary data sources used in this study are-Central Ground Water Board (CGWB) (http://cgwb.gov.in/gw_profiles/st_Punjab.htm); Statistical abstracts of Punjab (https://www.esopb.gov.in/static/Publications.html), various issues.

\section{Results And Discussion 4.1 Parameter settings}

Simulation experiments were performed to determine the best values of parameters for better performance in the investigated algorithms. The control parameter for NSGA-II and NSGA-III includes crossover probability (CR) and mutation probability =1/D (D is the number of decision variables). The maximum number of iteration for NSGA-II and NSGAlll was set at 100 and the population size was 40 . The parameter settings for both algorithms are summarized in Table 1.

Table 1

NSGA II and NSGA III parameter settings

\begin{tabular}{|lcll|}
\hline NSGA II & NSGA III & \\
\hline Population size & 40 & Population size & 40 \\
\hline Maximum number of iterations & 100 & Maximum number of iterations & 100 \\
\hline Crossover constant & 0.8 & Crossover constant & 0.8 \\
\hline & & Number of reference directions & 92 \\
\hline
\end{tabular}

\subsection{Experimental results}

NSGA-II and NSGA-III are used to decipher the multi-objective optimal crop plan problem that has been formulated in the current study. To assess the performance of the model in this work, the results of the algorithms are compared with each other. The NSGA-II and NSGA-III were implemented in PyCharm IDE using the Python programming language.

When considering multi-objective optimization, a graphical comparison should always be taken into account (Coello and Cortes, 2005). Two key assessment criteria (Adekanmbi et al., 2014) should be considered in particular in evaluating the Pareto fronts produced from a metaheuristic: (i) the placement of the solutions on the true Pareto front and (ii) uniform distribution of solutions across the Pareto front. The degree to which the points on the Pareto front are linearly correlated is the first evaluation criterion. The metaheuristic that produces a Pareto front with more linearly connected points is deemed the best at solving the multi-objective crop planning problem. This method is useful because it may reveal a linear relationship between groundwater consumption and net profit. The Pearson correlation coefficient can be used to measure the strength of a linear relationship between two variables such as groundwater and profit. The correlation coefficient is a value between -1 and 1 that reflects how strong the linear relationship between two variables, such as groundwater use and net profit, is. A higher positive score indicates a strong linear association in the same direction. As a result, we should expect increasing groundwater consumption to result in higher profit values. According to the second evaluation criterion, Pareto solutions should be evenly distributed.

The Pareto fronts for the meta-heuristics explored in this study are shown in Figures 2, 3, 4, and 5. The figures show that NSGA-III discovered a good distribution of solutions, and the correlation coefficient estimated for the Pareto front of NSGA-III is 0.9936, which is somewhat higher than the correlation value calculated for NSGA II, which is 0.9811 . As a result, NSGA-III had the best results, both in terms of solution distribution and placement on the Pareto front of the multi-objective optimal crop planning issue.

When the solutions do not converge to the true Pareto front of the problem, having a decent distribution of solutions becomes irrelevant (Raju et al., 2012). The solutions in Figures 2, 3, 4, and 5 converge on the Pareto front. On the Pareto optimum front, all of the results are equally good. All of the objectives can be met at the same time in the model. When one goal improves, the value of the other goal changes as well. From this list, a decision-maker must choose one solution to implement.

There can't be a single solution that achieves all of the goals in multi-objective optimization, but there exist sets of solutions that agree on non-dominated solutions as an alternative. When all of the goals are taken into account, the solutions are optimum in the sense that no other solution in the search space is

Page $4 / 10$ 
better than them. Higher-level decision-makers will be able to choose the best option based on factors such as water availability, the number of personnel available, equipment availability, capital available, and land acreage.

It is also clear from Figures 6, 7, 8 and 9 that the number of items in the Pareto front of NSGA-II (39 non-dominated solutions) is more than that of NSGA-III (13 non-dominated solutions). The number of non-dominated solutions indicates how good the algorithm is in producing desired results. Too many vectors (Van Veldhuizen and Lamont, 2000) may overwhelm the decision-makers while choosing from fewer solutions is easier.

\section{Conclusion}

The NSGA-II and NSGA-III methods of optimizing the basic linear, constrained crop planning problem were used in this research to study and analyze the results of multi-objective optimization models. In comparison to NSGA-Il, the following interpretations might be made about NSGA- III's performance: (i) It outperforms the NSGA-II in terms of producing almost true Pareto optimum fronts for the optimal crop planning problem under consideration; (ii) it generates a good distribution of results for multi-objective optimal crop planning problems. So, the NSGA-III may be concluded to be a realistic tool for assisting in the optimal crop planning decision-making process. The findings also demonstrated a straight-line relationship between groundwater use and profit. As a result, we should expect optimal levels of groundwater utilization to result in larger levels of net profit. In the future, it will be possible to apply other optimization techniques and compare the results to NSGA-III to determine its predominance over several other crop planning procedures.

\section{Declarations}

\section{Conflict of Interest and Authorship Confirmation Form}

- All authors have participated in (a) conception and design, or analysis and interpretation of the data; (b) drafting the article or revising it critically for important intellectual content; and (c) approval of the final version.

- This manuscript has not been submitted to, nor is under review at, another journal or other publishing venue.

- The authors have no affiliation with any organization with a direct or indirect financial interest in the subject matter discussed in the manuscript

Author's name Affiliation

Kamalika Nath ICAR-IASRI, New Delhi

Rajni Jain ICAR-NIAP, New Delhi

Alka Arora ICAR-IASRI, New Delhi

Himadri Shekhar Roy ICAR-IASRI, New Delhi

Sudeep Marwaha ICAR-IASRI, New Delhi

\section{Funding Statement:}

The author(s) received no financial support for the research, authorship, and/or publication of this article.

\section{Author's Contribution:}

All authors have participated in (a) conception and design, or analysis and interpretation of the data; (b)drafting the article or revising it critically for important intellectual content; and (c) approval of the final version.

\section{Availability of data and material:}

The study is mainly constructed on data composed from the "Comprehensive Scheme for Studying the Cost of Cultivation (CoC) of Principal Crops", Directorate of Economics and Statistics, Ministry of Agriculture, Government of India (https://eands.dacnet.nic.in/Cost_of_Cultivation.htm). Beneath this scheme, data were assembled from a sample of 300 farm households in 30 tehsils spread across three agro-climatic zones of Punjab. The other secondary data sources used in this study are-Central Ground Water Board (CGWB) (http://cgwb.gov.in/gw_profiles/st_Punjab.htm); Statistical abstracts of Punjab (https://www.esopb.gov.in/static/Publications.html), various issues.

\section{Code availability:}

Code will be avaible on request to the coresponding author.

\section{Ethics approval, Consent to participate, Consent for publication:}

The manuscript does not report on or involve the use of any animal or human data and "Not applicable" in this section.

\section{References}

1. Abayomi AO (2015) Differential evolution algorithm for optimal strategic decision making in crop farming system, Ph.D. thesis 
2. Adekanmbi OA, Olugbara 00, Adeyemo J (2014) A comparative study of state-of-the-art evolutionary multi-objective algorithms for optimal crop-mix planning. International Journal of Agricultural Science and Technology 2(1):8-16

3. Annepu Shi Y, Eberhart R (1998) A modified particle swarm optimizer. IEEE international conference on evolutionary computation proceedings. IEEE world congress on computational intelligence

4. Bao C, Xu L, Goodman ED, Cao L (2017) A novel non-dominated sorting algorithm for evolutionary multi-objective optimization. Journal of Computational Science, $23,31-43$

5. Coello CAC, Cortés NC (2005) Solving multiobjective optimization problems using an artificial immune system. Genet Program Evolvable Mach 6(2):163190

6. Coello CAC, Brambila SG, Gamboa JF, Tapia MGC, Gómez RH (2020) Evolutionary multiobjective optimization: open research areas and some challenges lying ahead. Complex \& Intelligent Systems 6(2):221-236

7. Deb K, Pratap A, Agarwal S, Meyarivan TAMT (2002) A fast and elitist multiobjective genetic algorithm: NSGA-II. IEEE Trans Evol Comput 6(2):182-197

8. Deb K, Jain H (2013) An evolutionary many-objective optimization algorithm using reference-point-based nondominated sorting approach, part l: solving problems with box constraints. IEEE Trans Evol Comput 18(4):577-601

9. Dutta S, Sahoo BC, Mishra R, Acharya S (2016) Fuzzy stochastic genetic algorithm for obtaining optimum crops pattern and water balance in a farm. Water Resour Manage 30(12):4097-4123

10. Fanuel IM, Mushi A, Kajunguri D (2018) Irrigation water allocation optimization using multi-objective evolutionary algorithm (MOEA)- a review. Int J Simul Multi Design Optim 9:A3

11. https://eands.dacnet.nic.in/Cost_of_Cultivation.htm

12. http://cgwb.gov.in/gw_profiles/st_Punjab.htm

13. https://www.esopb.gov.in/static/Publications.html

14. Jain H, Deb K (2013) An evolutionary many-objective optimization algorithm using reference-point based nondominated sorting approach, part Il: Handling constraints and extending to an adaptive approach.IEEE Transactions on evolutionary computation, 18(4),602-622

15. Jarin S, Khatun MK, Shafie AA (2006) Multi-objective constrained algorithm (MCA) and non-dominated sorting genetic algorithm (NSGA-ii) for solving multi-objective crop planning problem. ARPN Journal of Engineering and Applied Sciences 11:4079-4086

16. Kuo SF, Merkley GP, Liu CW (2000) Decision support for irrigation project planning using a genetic algorithm. Agric Water Manage 45(3):243-266

17. Lalehzari R, Boroomand Nasab S, Moazed H, Haghighi A (2016) Multiobjective management of water allocation to sustainable irrigation planning and optimal cropping pattern. Journal of Irrigation and Drainage Engineering, 142(1),05015008

18. Mansourifar M, Almassi M, Borghaee AM, Moghadassi R (2013) Optimization crops pattern in variable field ownership. World Applied Sciences Journal 21(4):492-497

19. Marko O, Pavlović D, Crnojević V, Deb K (2019) Optimisation of crop configuration using NSGA-III with categorical genetic operators. In Proceedings of the Genetic and Evolutionary Computation Conference Companion

20. Márquez AL, Baños R, Gil C, Montoya MG, Manzano-Agugliaro F, Montoya FG (2011) Multi-objective crop planning using pareto-based evolutionary algorithms. Agricultural Economics, 42(6),649-656

21. Mwiya RM, Zhang Z, Zheng C, Wang C (2020) Comparison of Approaches for Irrigation Scheduling Using AquaCrop and NSGA-III Models under Climate Uncertainty. Sustainability, 12(18),7694

22. Olakulehin OJ, Omidiora EO (2014) A genetic algorithm approach to maximize crop yields and sustain soil fertility. Net Journal of Agricultural Science 2(3):94-103

23. Oluwole AA, Oludayo 00, Josiah A (2014) A comparative study of state-of-the-art evolutionary multi-objective algorithms for optimal crop-mix planning. International Journal of Agricultural Science and Technology 2(1):1-9

24. Pal BB, Chakraborti D, Biswas P (2009) A genetic algorithm based hybrid goal programming approach to land allocation problem for optimal cropping plan in agricultural system. In International Conference on Industrial and Information Systems (ICIIS)

25. Raju KS, Vasan A, Gupta P, Ganesan K, Mathur H (2012) Multi-objective differential evolution application to irrigation planning. ISH Journal of Hydraulic engineering 18(1):54-64

26. Sadati SK, Speelman S, Sabouhi M, Gitizadeh M, Ghahraman B (2014) Optimal irrigation water allocation using a genetic algorithm under various weather conditions. Water, 6(10),3068-3084

27. Srinivas N, Deb K (1994) Muiltiobjective optimization using nondominated sorting in genetic algorithms. Evolutionary computation, 2(3),221-248

28. Sarker R, Ray T (2009) An improved evolutionary algorithm for solving multi-objective crop planning models. Computers and electronics in agriculture 68(2):191-199

29. Sarma AK, Misra R, Chandramouli V (2006) Application of genetic algorithm to determine optimal cropping pattern. Opsearch 43(3):320-329

30. Vafaeinejad A (2016) Cropping Pattern Optimization by Using of TOPSIS and Genetic Algorithm Based on the Capabilities of GIS. Iranian journal of Ecohydrology 3(1):69-82

31. Van Veldhuizen DA, Lamont GB (2000) On measuring multiobjective evolutionary algorithm performance. In Proceedings of the 2000 Congress on Evolutionary Computation. CECO0, 1, 204-211, IEEE

32. Wang XD, Hirsch C, Kang S, Lacor C (2011) Multi-objective optimization of turbomachinery using improved NSGA-II and approximation model. Comput Methods Appl Mech Eng 200(9-12):883-895

Page $6 / 10$ 
33. Wei W, Feng Y, Tan J, Li Z (2009) Product platform two-stage quality optimization design based on multiobjective genetic algorithm. Comput Math Appl 57(11-12):1929-1937

34. Xevi E, Khan S (2005) A multi-objective optimisation approach to water management. J Environ Manage 77(4):269-277

35. Yusoff Y, Ngadiman MS, Zain AM (2011) Overview of NSGA-Il for optimizing machining process parameters. Procedia Eng 15:3978-3983

36. Yuan Y, Xu H, Wang B (2014) An improved NSGA-III procedure for evolutionary many-objective optimization. In Proceedings of the 2014 annual conference on genetic and evolutionary computation

37. Zeng X, Kang S, Li F, Zhang L, Guo P (2010) Fuzzy multi-objective linear programming applying to crop area planning. Agric Water Manage 98(1):134142

\section{Figures}

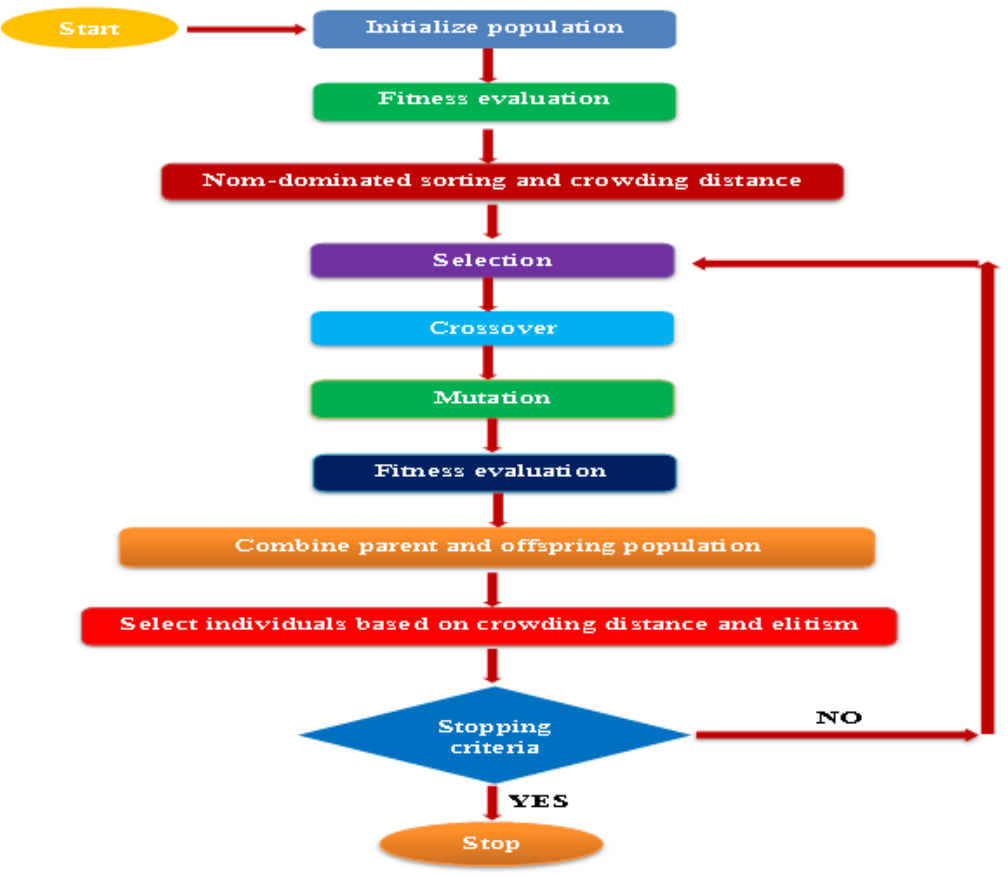

Figure 1

Flowchart of NSGA-II algorithm.

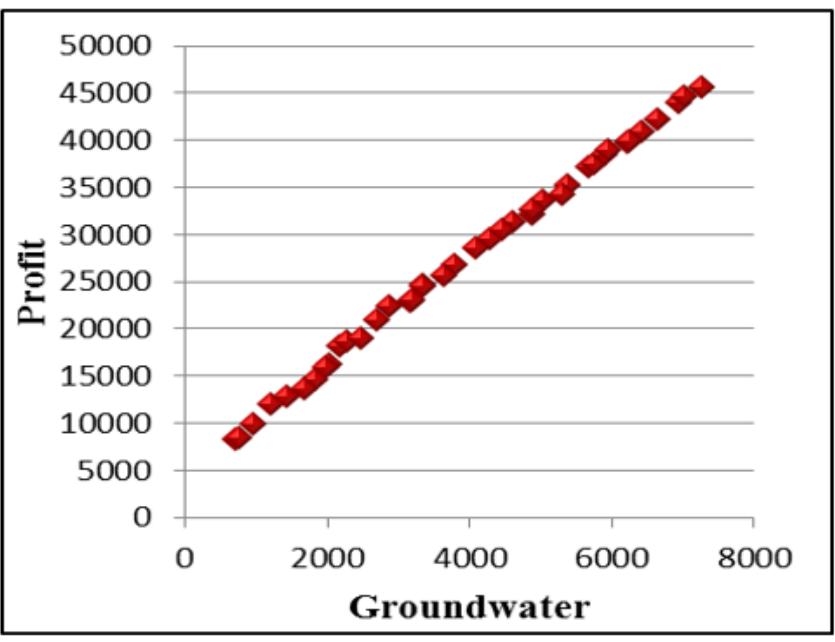

Figure 2

Pareto optimal front produced by NSGA-II for the crop planning model of Kharif crops when maximizing profit (Rupees per hectare) and minimizing groundwater use (cubic meter per hectare) 


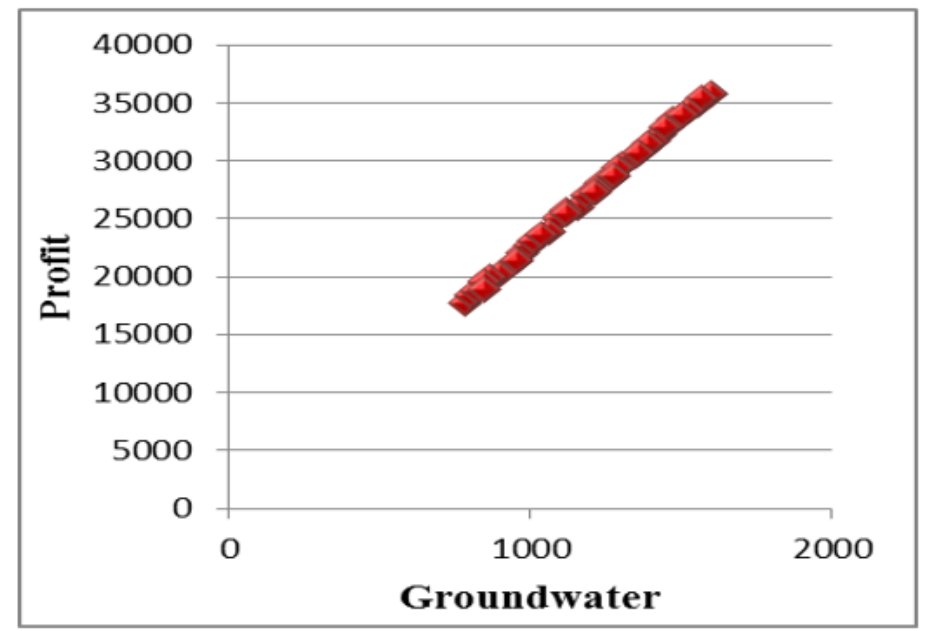

\section{Figure 3}

Pareto optimal front produced by NSGA-Il for the crop planning model of rabi crops when maximizing profit (Rupees per hectare) and minimizing groundwater use (cubic meter per hectare)

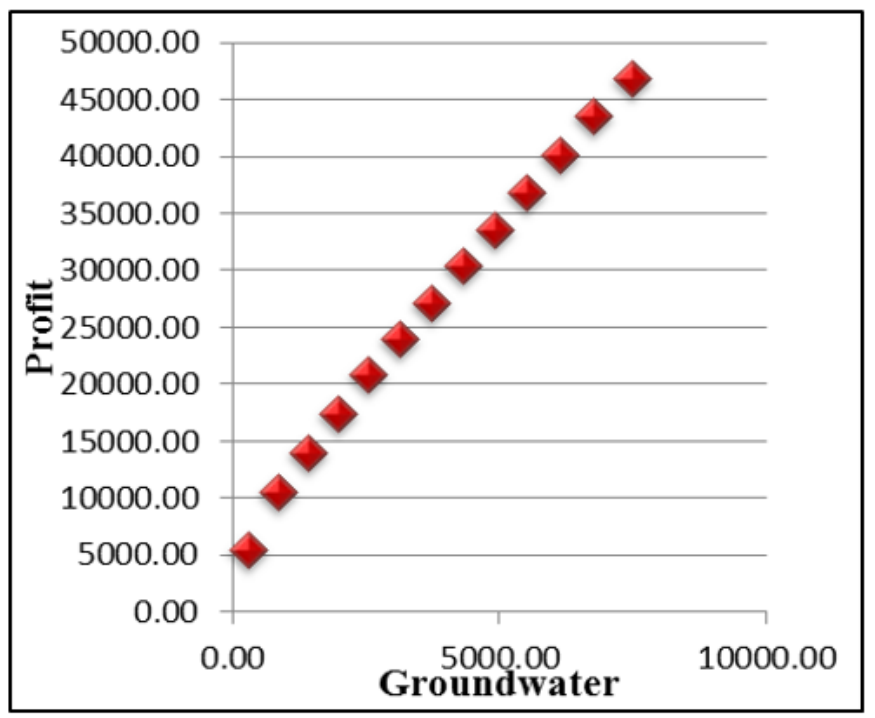

Figure 4

Pareto optimal front produced by NSGA-III for the crop planning model of Kharif crops when maximizing profit (Rupees per hectare) and minimizing groundwater use (cubic meter per hectare)

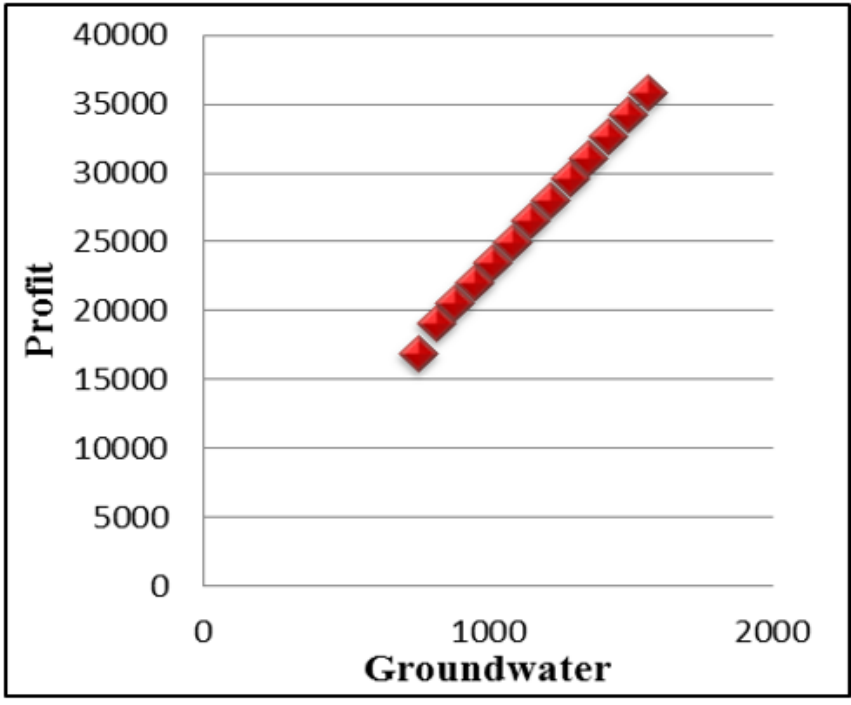


Figure 5

Pareto optimal front produced by NSGA-III for the crop planning model of rabi crops when maximizing profit (Rupees per hectare) and minimizing groundwater use (cubic meter per hectare)

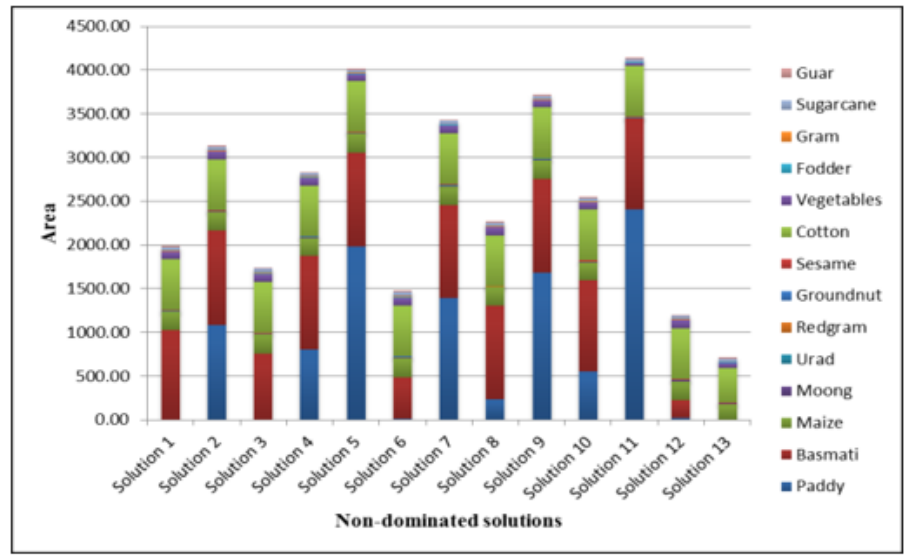

Figure 6

Planting areas (thousand hectares) as allocated to Kharif crops in the non-dominated solutions by NSGA-III

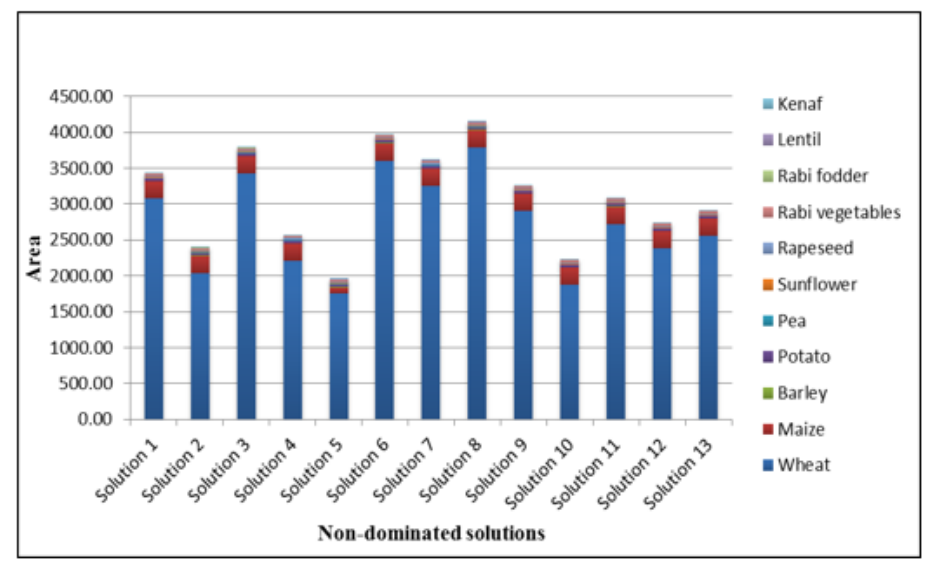

Figure 7

Planting areas (thousand hectares) as allocated to rabi crops in the non-dominated solutions by NSGA-III

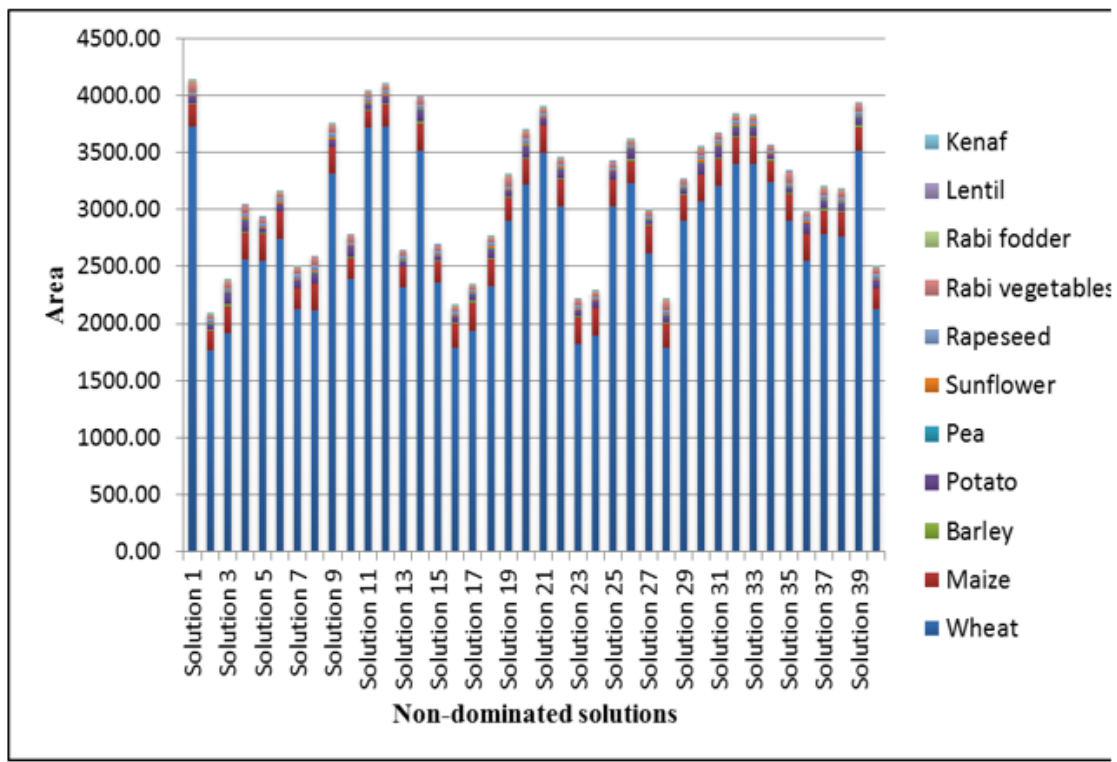


Figure 8

Planting areas (thousand hectares) as allocated to rabi crops in the non-dominated solutions by NSGA-II

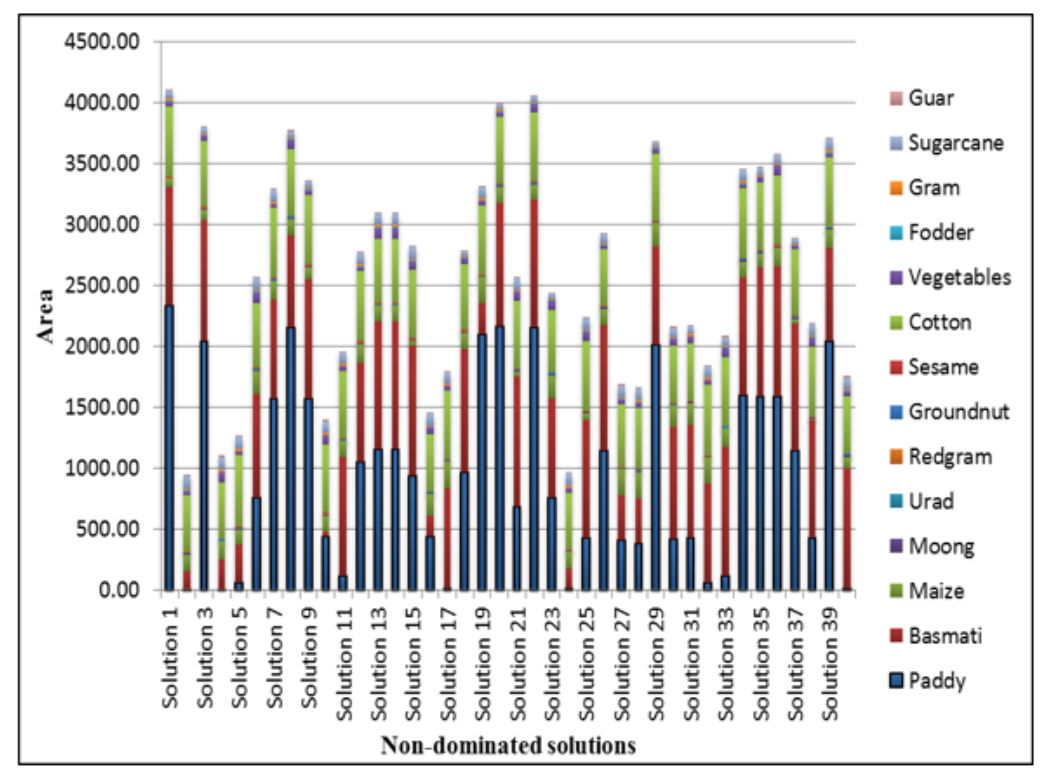

Figure 9

Planting areas (thousand hectares) as allocated to Kharif crops in the non-dominated solutions by NSGA-II 